\title{
PARTITIONES ORATORIAE: breves considerações
}

\author{
José Carlos Vasconcelos Siqueira Camboim ${ }^{1}$
}

\begin{abstract}
RES UMO: O presente artigo objetiva traçar breves considerações acerca da obra Partitiones Oratoriae, de Cícero, ressaltando a sua importância para a história do Dire ito Ocidental.
\end{abstract}

PALAVRAS-CHAVE: Direito Romano; História do Direito; Cícero; Retórica.

\section{PAR TITIONES ORATORIAE: briefly discusses}

ABSTRACT: This article aims to outline briefly discusses the work Partitiones Oratoriae, of Cicero, stressing its importance for the history of Western law.

KEY WORDS: Roman Law; Legal History; Cicero; Rhetoric.

\section{INTRODUÇÃO}

Cícero nos faz entrever, no seu De oratore, a imagem das obras de sua juventude (entre elas, De inventione) como já superadas pela evolução do pensamento do autor e pelo uso que se poderia fazer delas, ${ }^{2}$ além de seu método expositivo. ${ }^{3}$ No entanto, o referido método usado no De inventione, a saber, a coleção de preceitos técnicos, também se constitui na forma de seus últimos trabalhos sobre retórica, tanto das Partitiones Oratoriae quanto dos Topica. A obra das Partitiones Oratoriae foi elaborada em 45 a. C., e, de forma um tanto árida e breve, cobre todos os campos da retórica em boa parte tratando os tipos de casos, assuntos e argumentos. ${ }^{4}$

\footnotetext{
${ }^{1}$ Mestrando em Dire ito da UFRGS. Área de concentração: Fundamentos Teórico-filosóficos. Orientador: Prof. Dr. Alfredo de J. Flores.

${ }^{2}$ De oratore. lib. I, $\S 2^{\circ}, 5$, lin. 13-18, in: M. TVLLI CICERONIS. Rhetorica rec. brevq. adnot. crit. Instrvxit A. S. Wilkins, to mvs I, Oxonii e typographeo Clarendoniano, 1903.

3 Tal é o que se conclui da afirmação feita a propósito de como não trataria do que dedica o seu $d e$ oratore, como segue: "repetamque non ab incunabulis nostrae veteris puerilisque doctrinae quendam ordinem praeceptorum" (trad.: não repisarei, pelos nossos rudimentos de nossa antiga e pueril doutrina, uma certa ordem de preceitos), De orat. lib. I, $\S 6^{\circ}, 23$, lin. 31-1. Sobre a comparação entre as propostas do de inventione e as obras de maturidade de Cícero, vejamos o que escreve GRUBE: "When he wrote the De Oratore, we are told that 'he was dissatisfied with his first essay on rhetorical theory as too narrow and immature, and was no longer content with the mere technical precepts of the rhetoricians.' This was in 55 B.C., and it is true enough that the De Oratore, as well as the Brutus and the Orator, written a decade later, are much broader in conception and are largely concerned with matters of principle", in GRUBE, G. M. A. Educational, Rhetorical and Literary Theory in Cicero. Phoenix, 1962, XVI, p. 237.

${ }^{4}$ GRUBE, op. cit., p. 237. O tecnic is mo foi muito criticado pelos romanos, isso um tanto como atitude de reje ição à influência grega, no entanto, como acabamos de constatar no caso de Cícero (exceto quanto aos seus de oratore, Brutus e orator), os romanos não conseguiram fugir à influência daqueles. Cícero, em todas as suas obras técnicas do gênero "deal in great detail with the discovery of arguments or with arrangement, with inventio and dispositio, but that, with one exception [: orator], he nowhere deals with matters of style in any technical detail". Provavelmente, segundo GRUBE, o Cícero da oratória e do
} 
As Partitiones Oratoriae são consideradas, junto com os Topica, obras menores de Cícero no seu corpus retórico. E isto se deve ao fato de ambos serem trabalhos pedagó gicos e terem seu conteúdo atribuído (pelo próprio Cícero) a outras autoridades, respectivamente, escola acadêmica de filosofia e Aristóteles. ${ }^{5}$ Especificamente sobre as primeiras, trata-se de formidável introdução ao estudo da retórica formal antiga. ${ }^{6}$ Cícero tenciona prover a seu filho, Marcus, de uma iniciação teórica em retórica. ${ }^{7}$ Isto, a partir (é o que faz supor) de instância de seu filho para que lhe explique, em latim, sobre a arte do discurso (de ratione dicendi). ${ }^{8}$ As Partitiones podem ser consideradas como uma introdução ao De Inventione, sua primeira obra retórica. ${ }^{9}$

O presente artigo tem como objetivo descre ver algumas das lições presentes nas divisões de oratória do arpinense, particularmente sobre a invenção e colocação - no que diz com a força do orador -, e ainda algo sobre a ação do orator; sobre as formas intrínsecas e extrínsecas de convicção pelo disc urso, e as palavras simples e compostas; ainda, algo sobre as partes do discurso; as questões delimitadas e não delimitadas; e, enfim, sobre o discurso judicial. Nesta ultima, enfim, exporemos rapidamente algumas lições sobre disputas de conjetura, nome e qualidade de uma ação, de cuja acusação se faz em juízo, e, ainda, sobre as que se fundam em documento.

\section{AS DIVISÕES DA ARTE DA ORATÓRIA}

estilo, e não mais o da advocacia, não tinha em verdade muita paciência para com os tecnicismos do estilo, in: GRUBE, op. cit., p. 238.

${ }^{5}$ GAINES, Robert N. Cicero's partitiones oratoriae and topica: rhetorical philosophy and philosophical rhetoric. In: Brill's Companion to Cicero: Oratory and Rhetoric. Edited by James M. May. Leiden: Brill, 2002, p. 445. Neste artigo, GAINES objetiva mostrar que Cícero compusera as partitiones oratoriae e os topica com propósitos teóricos, destarte ajustando-se nitidamente dentro de seu programa intelectual em retórica. Pois, dado que por várias de suas obras retóricas, expôs diferentes visões da relação entre filosofia e retórica, GAINES concluíra que, no caso das partitiones oratoriae se Cícero teria pretendido utilizar a filos ofia para perscrutar a nature za da retórica, in: GAINES, op. cit., p. 445.

${ }^{6}$ GRA NT, William Leonard. The Partitiones Oratoriae of Cicero: an introduction and commentary. A thesis presented in partial fulfillment of the requirements for the degree of doctor of philosophy in the department of classics at the University of Toronto, June, 1943, p. 24-25. Texto disponível em: $<$ http://www.archive.org/details/partitionesorato00granuoft $>$. Acesso em 18.10.2009.

7 GAINES, op. cit., p. 449. Este autor defende a tese de que Cícero, além ou antes de ter intenções pedagógicas, pretendeu conceber o trabalho para representar filosofia retórica, op. cit., p. 449-450.

${ }^{8}$ Partitiones Oratoriae. I, $\S 1^{\circ}$, lin. 2. Utilizamos como referência a edição latina de WILKINS: M. TVLLI CICERONIS Rhetorica rec. brevq. adnot. crit. Instrvxit A. S. Wilkins, tomvs II, Oxonii e typographeo Clarendoniano, 1903.

9 "A useful companion to the treatise De Inventione is to be found in De Partitione Oratoria Dialogus, generally described as a catechism of rhetoric, according to the method of the Middle Academy, prepared by Cicero in the form of questions and answers, for the use of his son Marcus, probably about the close of the year 46 B.C. or the beginning of the year 45 B.C., shortly before the death of Tullia and the departure of Marcus for Athens", in: TA YLOR, Hannis. Cicero: a sketch of his life and works. A commentary on the roman constitution and roman public life, supplemented by the sayings of Cicero arranged for the first time as an anthology. Chicago: A. C. McClurg \& CO, 1916, p. 330. 
Cícero expõe introdutoriamente o tema acerca das partes nas quais se divide o ensino (doctrina) da oratória ${ }^{10}$, quais sejam: $\boldsymbol{\alpha}$ - a força do orador (vim oratoris): que trata das palavras e coisas que devem ser inventadas (invenienda) e colocadas (conlocanda $)^{11}$; corresponde ao campo de atuação do orador. ${ }^{12}$ No caso das coisas ou fatos, chama-se invenção, o inventar (invenire); para as palavras, elocução, o enunciar (eloqui). B- o discurso (orationem), que tem quatro partes: a narração (narratio) e a confirmação (confirmatio), que se cumprem para exibir ou apresentar (ad docendam); princípio ou exórdio (principium) e peroração (peroratio) se cumprem para mover as vontades ou paixões (ad impellendos animos); corresponde o discurso, portanto, às divisões do mesmo. ${ }^{13} \gamma$ - questão (quaestionem): pode ser infinita, chamada consulta (consultationem) e finita, chamada causa (causam). ${ }^{14}$ Esta divisão se considera das mais científicas dentre todas as obras retóricas de Cícero. ${ }^{15}$

\subsection{Sobre o orador e suas faculdades}

Decidimos aqui expor as idéias básicas de Cícero a respeito das faculdades do orador, ou seja, a invenção e a disposição (colocação) do inventado no discurso, bem

${ }^{10}$ GAINES traduz as referidas partes por power of speaker, the speech, the question, in: GA INES, op. cit., p. 450.

${ }^{11} \mathrm{O}$ colocar (conlocare) refere-se especialmente ao inventar (ad inveniendum refertur), in: part. I, $\S 3^{\circ}$, lin. 17-18. A lém disso, a voz, gestos e fisiono mia e tudo da ação estão associados à eloqüência; e de tudo a me mória é conservadora, In; part. I, § $3^{\circ}$, lin. 18-20.

12 GRANT, op. cit., p. 38.

13 GRANT, op. cit., p. 38.

14 Part. I, §3-4". "The whole of the art of rhetoric is therein arranged under three hands - the first treating of the subject in reference to the speaker (vis oratoris); the second, of the speech (oratio); the third, of the case (questio). The precepts with regard to the speaker are then ranged under five heads - invention, collocation, eloquutio, actio, memoria; while the precepts with regard to the speech itself are also arranged under five heads - exordium, narratio, confirmatio, reprehensio, peroratio. The case may be infinita, in which neither persons nor times are defined; or it may be finita, in which the persons are defined, when it is called causa. The precepts with regard to the questio infinita are then ranged under two heads; and the precepts with regard to the questio finita under three heads", in: TA YLOR, Hannis, op. cit., p. 331. No entanto, podemos considerar a digressão, entre as categorias do discurso, como ENOS o faz: "(...) Cicero established a seven (not six) part pattern for arranging compositions: exordium, narratio, partitio, confirmatio, reprehensio, an optional digressio, and conclusio". Isto quanto ao De inventione; "and he [Cícero] modified his pattern of arrangement significantly in Partitiones Oratoriae and encouraged great flexibility in structuring compositions to the situation (...)", in: ENOS, Richard Leo. Ciceronian Dispositio as an Architecture for Creativity in Composition: A note for the Affirmative. In: Rhe toric Review, vol. 4, $\mathrm{n}^{\circ} 1$ (Sep., 1985), p. 108.

15 "Such partitiones, corresponding to the Greek $\delta 1 \alpha 1 \rho \varepsilon ́ \sigma \varepsilon 1 \varsigma$, are considered to be the most purely scientific of all Cicero's rhetorical works, despite the tediousness and obscurity of the tract as a whole, which is poor in illustrations and highly technical in its details", in: TA YLOR, Hannis, op. cit., p. 331. 
como breves linhas sobre a ação retórica (os gêneros de elocução) e, ulteriormente, exploraremos a respeito dos gêneros de argumentar. Com efeito, não prejudicaremos a estrutura do trabalho em três momentos de desenvolvimento, além de conservarmos a unidade destes aspetos da atividade do orador.

\subsection{Sobre a invenção e colocação}

Com a invenção, o orador faz crer (fidem faciat) àqueles aos quais deseja persuadir e causar movimento da alma (motum eorum animis afferat). Mas, para persuadir, aquele que discursa deve lançar mão dos argumentos ou provas tirados dos lugares (ducuntur ex locis) ou naturais (insitis), ou emprestados, extrínsecos (assumptis), ${ }^{16}$ de onde um argumento (o inventado persuasivo para fazer crer) está escondido. ${ }^{17}$ Ademais, a invenção se destina não somente à descoberta de argumentos, mas também à aquisição de todo tipo de assunto apropriado ao caso. ${ }^{18}$

Cícero considera os tipos de provas ( $\boldsymbol{\alpha}$ ) extrínsecas (remota) como provas sem arte, $e . g$. testemunhos, em outras palavras, provas cuja natureza é exterior à coisa; ${ }^{19} \mathrm{e}$ $\boldsymbol{\beta}$ ) intrínsecas, que são inerentes, de direito, à própria coisa ou fato. ${ }^{20} \mathrm{De}$ ambos os gêneros de lugares (exterior ou interior à coisa) ${ }^{21}$ se tomam os argumentos. ${ }^{22}$ Observemos que Cícero textualmente considera como lugar a fonte dos argumentos. ${ }^{23}$

\footnotetext{
16 MENÉNDEZ traduz adsumptus no sentido de fatos ou provas "extrínsecos", que parece ser mais adequado considerado os parágrafos seguintes, in: OBRAS COMPLETAS DE MARCO TULIO CICERÓN. Trad. D. Marcelino Menendez Pelayo.Tomo XIV (t. I da tradução). Madrid: Librería de los sucessores de Hernando, 1924, p. 240.

${ }^{17}$ Part. II, $\$ 5^{\circ}$, lin. 4-10.

18 GRANT, op. cit., p. 38-39. Os passos a serem seguidos para a invenção constam do diálogo De Oratore, liv. II, in: op. cit., p. 39-42.

${ }^{19}$ Existem dois gêneros de testemunhos: divino e humano. Exemplos de divino: os oráculos, os auspícios, vaticínios, respostas dos sacerdotes (e também dos harúspices e adivinhos). Exe mplos de humano são: o testemunho que se funda da autoridade, ou da vontade, em declaração livre, ou formal (segundo MENÉNDEZ, "palabras tácitas o expresas", p. 241). Entre as formais: escritos, pactos, promess as, juramentos e quesitos, in: part. II, $\S 6^{\circ}$, lin. 10-18.

${ }^{20}$ Part. II, $\S 6^{\circ}$, lin. 19-20. Quae [iura] insita sunt rebus ipsis, (...).

${ }^{21}$ Exemp los de prova ou fatos intrínsecos: defin ição, contrariedade, semelhança ou não, a conformidade ou não, as coisas quase unidas, as quase contrárias, as causas, os efeitos das causas, as distribuições (como os gêneros das partes, ou partes dos gêneros), as origens das coisas, os quase antecedentes, nos quais há um algo de argu mento como nas comparações a maior, ao par, a menor, em co mparações sobre a natureza das cois as, ou faculdades, in: part. II, $\S 7^{\circ}$.

${ }^{22}$ Part. III, $\S 8^{\circ}$, lin. 29-31.

${ }^{23}$ Part. II, § 5 $5^{\circ}$ lin. 08-09.
} 
A colocação ${ }^{24}$ está intimamente conectada com a invenção, e se define como a ordem em divisão das coisas inventadas. ${ }^{25}$ Sobre a colocação, Cícero afirma que se devem aplicar as questões finitas, também chamadas definidas (definita) que servem para mover as vontades, paixões (motus animorum). ${ }^{26} 27$ A colocação das provas nas questões definidas (causae) se dará conforme o fim a almejar, se produzir medo, desejo, etc. Para tanto, se deverá perscrutar sobre o tipo de auditório, ${ }^{28}$ se juízo, deliberação (suasione) e demonstrativo ou laudatório, ${ }^{29}$ pois nestes, se visa, respectivamente: a fúria (saevitiam) ou clemência (clementiam); esperança (spem) ou apreensão (reformidationem); e deleite (delectationem). ${ }^{30}$

Para o gênero judicial, a colocação se dá diferentemente para o acusador e para o réu. ${ }^{31}$ No caso do acusador, a exposição dos fatos segue a ordem destes fatos (rerum ordinem persequitur); ademais, expõe cada argumento com veemência; se detém nas provas, forte nas tábuas, decretos, testemunhos, com muita detenção; na peroração é veemente, sendo útil uma breve digressão; tudo se faz com o fim de despertar a fúria do juiz (ut iratum efficiat iudicem). ${ }^{32}$ No caso do réu, seu exórdio deve procurar obter a benevolência (ad benevolentiam conciliandam); sua narração deve cortar as coisas que prejudicam (amputandae quae laedunt), ou abandonar (relinquendae) tudo que é embaraçoso na sua peroração; as provas (firmamenta) devem ser refutadas (diluenda), ou obscurecidas (obscuranda), ou confundida com digressões (digressionibus obruenda); as perorações devem ser destinadas para a misericórdia. ${ }^{33}$

\footnotetext{
${ }^{24}$ GAINES traduz conlocare por arrangement, in: GA INES, op. cit., p. 451.

${ }^{25}$ GRANT, op. cit., p. 42. “(...) rerum inventarum in ordinem distributio”. Ainda, a colocação e a invenção não são exclusivas da arte da oratória, ao contrário da pronúncia (elocutio) e ação (actio), in: op. cit., p. 43.

${ }_{26}$ Ầs questões infinitas a colocação (ordem dos lugares) é a mesma de lineada in: part. $\S 6^{\circ}-7^{\circ}$.

${ }^{27}$ Neste ponto, Cícero faz distinção entre convicção e persuasão: convencer é o que faz crer (fides facere), é opinião firme (firma opinio). Por outro lado, persuasão é instigação, movimento da alma (motus autem animi incitatio) sobre a vontade, o pesar, o medo, o desejo. As considerações de Cícero, para as causas, levarão e m conta o que serve comu mente para convencer e persuadir, in: part. III, $\S 9^{\circ}$, lin. 10-12, 15-17.

${ }^{28}$ MENÉNDEZ traduz auditorum genere por "calidad del auditorio", in: op. cit., t. XIV, t.2, p. 242.

${ }^{29}$ Part. III, $\$ 10^{\circ}$.

${ }^{30}$ Part. IV, $\$ 11^{\circ} .25-27$.

31 A colocação para o gênero demonstrativo deve variar conforme se guarde a ordem dos tempos (temporum servantur gradus); as distribuições dos gêneros; também se se acende dos menores aos maiores, ou se se desce dos maiores aos menores; ainda, se distinguimos com variedade e desordem, inserimos o pequeno com o grande, o simples com o reunido, o obscuro com o claro, o alegre com o triste, o incrível com o provável, in: part. IV, $\S 12^{\circ}$, lin. 1-7. Na colocação para o gênero deliberativo, ou se prefere o exórdio (principia) sucinto, ou inexistente (vel non longa vel saepe nulla), pois se supõe do público algu ma informação prévia; a narração também não deve ser longa, e pode ser de coisas passadas e futuras, e o conselho (suasio) de coisas futuras, in: part. IV, $\S 13^{\circ}$, lin. 7-11.

${ }^{32}$ Part. IV, \& $14^{\circ}$.

${ }^{33}$ Part. V, \$15 . Lin. 22-27.
} 


\subsection{Sobre a elocução}

Cícero, a partir de então, trata dos preceitos da oração e das palavras. Há dois gêneros de elocução: $\boldsymbol{\alpha}$ - um gênero é solto ao natural (sua sponte fusum), que tem sua força nas palavras simples, que devem ser inventadas (invenienda sunt); B- o outro é mudado e figurado (versum atque mutatum), em palavras compostas (coniunctis), que, por sua vez, devem ser colocadas, arranjadas (conlocanda est). ${ }^{34}$

\subsubsection{Modos de distinguir as palavras}

As palavras simples se dividem em $(\boldsymbol{\alpha})$ naturais e em $(\boldsymbol{\beta})$ inventadas, trasladadas (simplicia verba partim nativa sunt partim reperta): as que são naturais são significadas pelo sentido; as inventadas são feitas e transformadas por semelhança (similitudine), ou imitação (imitatione), ou desvio (inflexione), ou união das palavras (adiunctione verborum). ${ }^{35}$ Ainda, as palavras podem ser distinguidas ou pela natureza (natura), ou pelo seu tratamento, uso (tractatione). Pela natureza se considera as palavras mais sonoras ou harmoniosas (sonantiora), as maiores, as mais brandas (leviora), as mais polidas (nitidiora), outras ao contrário. ${ }^{36}$ Pelo seu tratamento, seja ou quando são adotadas as próprias denominações das coisas, ou acrescentadas, ao lado do nome, novas ou antigas, ou modificadas ou desviadas por algum modo pelo orador, seja por metáfora, ou por metonímia, ou aquelas das quais utilizamos em excesso, ou aquelas que tornamos obscuro, que erguemos de um modo não crível, cada qual mais extraordinária que se nos permite o costume da língua. ${ }^{37}$

Quanto às palavras compostas, deve-se cuidar as quantidades (numeri) e colocação ou disposição (consecutio). A quantidade é regrada pelo ouvido, a se evitar que a fala do orador seja incompleta em relação ao que ele se propunha, em outras palavras, ele seja lacônico, ou, por outro lado, que o exceda, isto é, que seja prolixo e redundante. Acerca da colocação das palavras, o objetivo é não prejudicar a oração com

\footnotetext{
${ }^{34}$ Part. V, $\$ 16^{\circ}$, lin. 1-4.

${ }^{35}$ Part. V, $\$ 16^{\circ}$.

${ }^{36}$ Part. V, \$16-17 , lin. 8-11.

${ }^{37}$ Part. V, $\$ 17^{\circ}$, lin. 11-17.
} 
relação aos gêneros, números, tempos, pessoas e casos, sob pena de censura (quod non est consequens vituperandum est $).{ }^{38}$

Existem cinco guias, cânones (quasi lumina), que valem tanto para as palavras simples como para as compostas, a saber: o claro (dilucidum), o sumário (breve), o provável (probabile), o evidente (inlustre) e o harmonioso (suave). $\alpha$ - o claro se obtém com palavras dispostas ou encerradas em períodos (circumscriptione), ou em frases cortadas (intermissione), ou em incisos (concisione). Daí resulta que a obscuridade consiste no comprimento largo (longitudine), ou abreviação da oração (contractione orationis), ou ambigüidade, ou inflexão, desvio (inflexione), ou mudança das palavras (immutatione verborum). $\boldsymbol{\beta}$ - o sumário se obtém com palavras simples que se devem dizer uma só vez. $\boldsymbol{\gamma}$ - o provável é gênero da oração se não é ataviado e ornado demais, se nas palavras há autoridade e peso, se as sentenças são graves ou adequadas às opiniões e costumes dos homens. $\boldsymbol{\delta}$ - o evidente possui palavras escolhidas com seriedade (verba gravitate delecta), pois trata de estabelecer a coisa, fato, como se à vista do público; assim, atinge-se diretamente as sensações e, inclusive, pode mover o próprio juízo (mens ipsa moveri potest). ${ }^{39} \boldsymbol{\varepsilon}^{-}$o harmonioso será o primoroso em elegância e graça de palavras sonantes e brandas (verborum sonantium et levium), sem asperezas, hiatos e sem longos giros, com similitude e proporção entre as palavras. ${ }^{40}$

\subsubsection{Sobre a oração mudada e figurada (de conversa oratione atque mutata)}

Este gênero de oração consiste na mudança das palavras (commutatione verborum). Nas palavras simples se usa para dilatar a oração pela palavra, ou contração das palavras. Nas palavras compostas (coniunctis), pode se empregar tríplice mudança, no que diz com a ordem: direta (directe), indireta (invertatur ordo); e por partes e misturado (intercise atque permixte). ${ }^{41}$

\subsubsection{Sobre os preceitos do discurso (de orationis praeceptis)}

\footnotetext{
38 Part. VI, $\S 18^{\circ}$.

39 Part. VI, \$19-20. Sobre "o evidente", Cícero afrima serem os preceitos de "o claro" aplicáveis àquele. E mais, sustenta que "o evidente" vale um pouco mais do que "o claro" (plus aliquanto inlustre quam illud dilucidum). Neste ponto, decidimos contrariar o sentido traduzido por MENÉNDEZ, que o entendeu por "tanto más ilustre [ou evidente] es una cosa, cuanto es más clara", in: op. cit., p. 244.

${ }^{40}$ Part. VI, $\$ 21^{\circ}$, lin. 14-18.

${ }^{41}$ Part. VII, $\$ 22-23^{\circ}$.
} 
De acordo com Cícero, o discurso tem quatro partes. Duas se destinam a mover a vontade, paixão, provocada a saber, pelos exórdios (initiis) e perorações (perorationibus). Essas são a primeira (o exórdio) e a última parte (a peroração). A segunda é a narração (narratio) e a terceira, a confirmação (confirmatio), e se prestam a fazer crer a oração. ${ }^{42} \boldsymbol{\alpha}$ - o exórdio se toma das pessoas ou das próprias coisas (ou fatos), bem como se dá por razão de três coisas, fins: para que o orador seja ouvido amigavelmente, de um modo inteligente, e atentamente. ${ }^{43}$ B- a narração é a explicação das coisas, e como que o fundamento que se deve seguir para o convencimento (fundamentum constituendae fidei). Deve-se narrar claramente e com verossimilhança, bem como se recomenda a brevidade. ${ }^{44} \gamma$ - a confirmação consiste em se querer provar a causa; ao que a refutação, em destruir o argumento contrário. $\boldsymbol{\delta}$ - a peroração é dividida em duas partes: amplificação e enumeração. ${ }^{45} \mathrm{~A}$ amplificação, que tem seu próprio lugar na peroração, mas também pode se dar em qualquer lugar após a confirmação ou refutação, "é, pois, uma certa afirmação mais carregada que procura obter, pelo movimento dos ânimos, o crível no dizer". ${ }^{46}$ A enumeração tem lugar em dois momentos: quando o orador desconfia da memória do ouvinte; ou, passado um tanto de tempo, ou longa duração do discurso, ou em provas acumuladas, brevemente expostas há de ter a causa maior força. ${ }^{47}$

\subsubsection{Sobre os meios de fazer crer}

Acerca dos meios de persuasão, Cícero afirma que se dividem em confirmação (confirmationem) e refutação (reprehensionem). Naquela queremos provar nossa causa; nesta, refutar a contrária. Ademais, em toda controvérsia ou se indaga algo seja ou não seja (sit necne sit); ou que seja (quid sit); ou qual seja (quale sit). Respectivamente, portanto, são chamados de conjetura (coniectura), questão de fato; definição (definitio), questão sobre nome de fato; e razão (ratio). ${ }^{48}$ Destas três questões, basicamente, são

\footnotetext{
${ }^{42}$ Part. VIII, $\S 27^{\circ}$, lin. 4-8.

${ }^{43}$ Part. VIII, §28 , lin.16-19.

${ }_{45}^{4}$ Part. IX, §31 ${ }^{\circ}$, lin.13-14.

45 Part. XV, $\$ 52^{\circ}$, lin. 25-26. A peroração (...) est divisa in duas partes, amplificationem et enumerationem.

${ }^{46}$ Part. XV, $\S 53^{\circ}$, lin. 29-30. Est igitur amplificatio gravior quaedam adfirmatio, quae motu animorum conciliet in dicendo fidem.

47 Part. XVII, §59 . Neste ponto discordamos da tradução de MENÉNDEZ, que entendeu a locução firmamentis orationis como Acusativo plural + Genitivo singular; e, ainda esquecera o adjetivo frequentatis, que, por outro lado, deve acompanhar o substantivo firmamentis, in: op. cit., p. 253.

${ }^{48}$ Part. IX, §33․
} 
inventados os argumentos que têm por fim fazer crer (unde inveniuntur quae ad fidem pertinent). ${ }^{49} \mathrm{~A}$ conjetura consiste nas verossimilhanças (in veri similibus) $\mathrm{e}$ características próprias das coisas (in propriis rerum notis). $\mathrm{O}$ verossímil é o que quase sempre de tal modo aconteça (quod plerumque ita fiat). Quanto ao argumento de caráter próprio, digamos que nunca seja de outro modo e mostre certo (nunquam aliter sit certumque declaret). ${ }^{50}$

A definição consiste em que se elucide o que é próprio dentre o que é de gênero, propriedade ou também freqüentemente de qualidades comuns. Se a controvérsia gira em torno de qualidades próprias, comumente se define por contrariedade (ex contrariis), dessemelhança (ex dissimilibus) e por igualdade (ex paribus) ${ }^{51}$ Neste gênero também são freqüentemente convenientes as descrições (descriptiones), enumeração das consequiências (enumeratio consequentium) e a explicação do vocábulo e do nome (explicatio vocabuli ac nominis). ${ }^{52}$

No caso que seja posto em dúvida de que natureza são as coisas (qualia sint vocatur in dubium $)^{53}$, tratar-se-á de questão de gênero ${ }^{54}$, que poderia ser ou negar um fato de Direito, ou uma vingança por motivo de cólera, piedade, ou honra, ou religião, ou algo feito em nome da pátria, ou, ainda, por necessidade, ignorância ou, mesmo, acaso. ${ }^{55}$ Os atos sem razão não têm defesa em juízo legítimo. Dos atos de razão se disputa sobre ter sido legítimo e reto; daí a razão pela qual se deve lançar mão dos lugares mencionados. ${ }^{56}$

\subsubsection{Sobre os gêneros de argumentar}

Os gêneros de argumentar se dividem em extrínsecos e intrínsecos (ou naturais).

\subsubsection{Argumentação intrínseca}

\footnotetext{
${ }^{49}$ Part. XIII, $\S 45^{\circ}$.

50 Part. X, $\$ 34^{\circ}$. Os argumentos de verossimilhança se encontram em pessoas, lugares, tempos, fatos, eventos, natureza das coisas mesmas e negócios.

${ }^{51}$ Part. XII, $\S 41^{\circ}$.

52 Part. XII, $\$ 41^{\circ}$, lin. 1-4.

53 Part. XII, $\$ 42^{\circ}$, lin. 6-7.

${ }^{54} \mathrm{Cf}$. De Inventione, IX.

55 Part. XII, $\S 42^{\circ}$, lin.9-11. Aut iure factum depellendi aut ulciscendi doloris gratia aut pietatis aut pudicitiae aut religionis aut patriae nomine aut denique nece ssitare inscitia casu.

${ }^{56}$ Part. XIII, $\$ 42^{\circ}$, lin.12-14.
} 
A argumentação é a explicação do argumento, e se a obtém quando tomado o que não é duvidoso ou provável se conclui algo por si ou duvidoso ou menos provável. Dois são os gêneros de argumentar: um tem relação diretamente com fazer crer, o outro se dirige para mover. Sobre o primeiro - argumento direto -, tem a estrutura de um silogismo, tal como Cícero o expressou, que segue: "o direto, pois, como propôs algo que provar e toma [argumentos] com os quais se sustenta e, isto confirmado, se tornou de volta ao seu argumento e concluiu". 57 A outra argumentação, para mover a vontade do ouvinte, segue: "[a]quela outra argumentação, como se em sentido contrário e em oposição: antes toma o que deseja e confirma os [argumentos], depois disto que deveu ser proposto, lança ao propósito perturbando os ânimos". 58

\subsubsection{Argumentação "sem arte” ou extrínseca}

A argumentação sem arte, não obstante nasça de uma arte, é assim chamada por não ser obtido da arte oratória, e consiste principalmente em testemunhos. Gênero de testemunhos é o mais débil; é baseado na vontade, enquanto que os argumentos extrínsecos são próprios das coisas. Ademais, há testemunhos que não são acreditados, que poderiam ser devidos a ira, medo, visando-se prêmio, etc. ${ }^{59}$

\section{LUGAR DAS QUESTÕES (QUAESTIONIS LOCUM) ${ }^{60}$}

Os gêneros de questões são dois: um delimitado por pessoas e tempos (finitum); e outro não delimitado por pessoas e tempos (infinitum), ou seja, sem pessoas e tempos. O gênero delimitado se chama causa (causam); o não delimitado se denomina tese (propositum) ${ }^{61}$ No entanto, a tese - objeto duma deliberação ou tese - é quase uma parte

\footnotetext{
57 Part. XIII, $\$ 46^{\circ}$, lin. 11-13. Derecto igitur, cum proposuit aliquid quod probaret sumpsitque ea quibus niteretur, atque his confirmatis ad propositum sese rettulit atque conclusit.

${ }^{58}$ Part. XIII, $\$ 46^{\circ}$, lin. 13-16. Illa autem altera argumentatio quasi retro et contra prius sumit quae vult eaque confirmat, deinde id quod proponendum fuit permotis animis iacit ad extremum.

59 Part. XIV, $\$ 48-49^{\circ}$.

${ }^{60}$ Todos os lugares do gênero de questões delimitadas, quanto à invenção, são os mesmos dos argumentos de fazer crer. Sobre a colocação dos argumentos, o que foi referido anteriormente se aplica aqui também, in: Part. XX, $\S 68^{\circ}$.

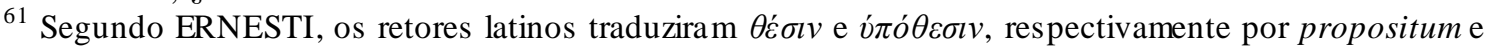
causam, in: ERNESTI, Johann Christian Gottlieb. Lexicon technologiae Latinorum rhetoricae: congressit et animadversionibus illvstravit Io. Christ. Theoph. Ernesti philos. Prof. Lips. Lipsiae: Sv mtibus Caspari Fritsch, 1797, p. 317. Por seu turno ao tratarem brevemente das declamationes, MURISON e ABERDEEN afirmam, como segue: "Cicero divides the themes into causae, definite cases, i.e. limited as to time, place, person, and circumstances generally; and proposita, indefinite, unlimited", in: MURISON,
} 
da causa e da controvérsia, pois o indefinido existe no definido e todas as coisas se referem àquilo - ao indefinido. ${ }^{62}$ A tese se divide em dois gêneros: de conhecimento (cognitionis) que tem a ciência como fim; e de ação (actionis), que se refere ao fazer. A tese de conhecimento se subdivide em três espécies: que seja ou não seja (sit necne sit); o que seja (quid sit); e como seja (quale sit). A tese de ação, por seu turno, possui dois gêneros: um para perseguir ou para evitar algo; outro se refere a algo bom ou útil. ${ }^{63}$

$\boldsymbol{\alpha}$-a tese de conhecimento em que se pergunta "seja ou não seja, foi, ou que há-de ser", ${ }^{64}$ pois, possui dois gêneros de questões: se algo pode se dar (possitne aliquid effici); ou de que modo cada [coisa] seja feita (quem ad modum quidque fiat). Neste último entram todas as questões obscuras e naturais que se discutem as razões e causas das coisas. ${ }^{65} \boldsymbol{\beta}$ - a tese de conhecimento em que se pergunta "que seja" tem dois gêneros: se deve discutir se outro seja o mesmo, ou seja, se algo é como outra coisa. Do outro gênero se faz a descrição como que representando a imagem, e.g. o que seja soberbo (quid sit superbus). ${ }^{66} \gamma$ - a tese de conhecimento, em que se pergunta "como seja", deve ser discutido ou sobre a honestidade, ou utilidade, ou eqüidade. Além, também se discute por comparação (ex comparatione), e.g. que mais honesto, ou que mais honestíssimo. ${ }^{67} \boldsymbol{\delta}$ - a tese de ação tem um gênero que diz com a razão do dever, e.g. por qual modo sejam de venerar os pais (ut quem ad modum colendi sint parentes). $\varepsilon$ - a tese de ação te outro gênero que se refere a sedar as paixões e para acalmar pelo discurso $(\mathrm{ad}$ sedandos ânimos et oratione sanandos). ${ }^{68}$

\subsection{O gênero de causa judicial}

O gênero judicial tem o mesmo objeto do gênero deliberativo, a saber, o direito para que se cumpra, prove e obtenha o que sustenta. ${ }^{69} \mathrm{E}$, ao contrário do deliberativo, aplica-se à discussão de fatos passados. ${ }^{70} \mathrm{O}$ fim do gênero judicial é precisamente, a equiidade (aequitas). Às vezes, se julga por comparação, ou seja, se perquire o mais

William et ABERDEEN, M. A. Education. In: A companion to Latin Studies. Ed ited for the syndics of the University Pree by John Edwin Sandys. Cambridge at the University Press, 1910, p. 234-235.

${ }^{62}$ Part. XVIII, $\$ 61^{\circ}$.

${ }^{63}$ Part. XVIII, $\$ 62^{\circ}$.

${ }^{64}$ (...) sit necne sit aut fuerit aut futurumve sit (...), in: Part. XIX, $\S 64^{\circ}$.

${ }^{65}$ Part. XIX, $\$ 64^{\circ}$.

${ }^{66}$ Part. XIX, $\$ 65^{\circ}$.

${ }^{67}$ Part. XIX, $\$ 66^{\circ}$.

${ }^{68}$ Part. XIX, $\$ 67^{\circ}$.

${ }^{69}$ Part. XX, $\$ 69^{\circ}$, lin. 4-5. (...) ius, ut obtineat probet efficiat quod agit.

${ }^{70}$ Part. XX, $\$ 69^{\circ}$, lin. 13-14. 
eqüitativo, ou o mais eqüitativo entre todas as soluções. ${ }^{71}$ As questões como a que vimos sobre eqüidade por comparação (de comparanda aequitate), ${ }^{72}$ ou também questões outras, como a de a ação ser segundo a lei, que devem ser tratadas segundo Cícero preferentemente antes da formação dos juízos (ante iudicium tractanda videantur); bem como as questões em juízo, todas, em que se disputa sobre o direto civil ou o bom e eqüitativo (de iure civili aut de aequo et bono), versam sobre a qualidade da coisa. ${ }^{73}$

Em todas as causas há três graus, dos quais pelo menos um se pode extrair para resistir o réu em juízo: negar o fato que se opõe; ou confessado, negar o sentido que o adversário acusa ser; ou, ainda, negar a qualidade atribuída pelo acusador ao fato e, alegar a retidão, ou defender que deve ser perdoado. ${ }^{74}$ Respectivamente, se trata de estado ou quase conflito (status et quasi conflictio) acerca de conjetura (coniectura); de definição e explicação ou etimologia da palavra (definitione [aut descriptione] atque informatione verbi); de defender a causa pelo eqüitativo, o reto e humano visando o perdão (aequi et recti et humani ad ignoscendum). ${ }^{75}$ Estas três, somadas às razões expostas pelo acusador - sem a qual não existiria causa, consistem na matéria das causas (continentia causarum). ${ }^{76}$ Especificamente quanto ao réu se chama razão (rationem), e quanto ao acusador, confirmação (firmamentum), que se lança contra a razão, visando a destruí- la. ${ }^{77}$ Do conflito (ex conflictione) da razão e confirmação nasce a controvérsia (disceptationem), neste momento se costuma indagar que coisa vem a juízo (quid veniat in iudicium) e sobre o que se controverte (de quo disceptetur).

Quanto às provas mais importantes (gravissimis firmamentis) destacam-se das de escritos de lei, ou de testamento, ou de juiz, ou de alguma estipulação, ou fiança. Tal porque uma simples questão de conjetura, a saber que se nega um feito, não se pode argüir por escrito (argui non potest scripto); ou, ainda, por uma simples questão de definição, em que se trata da interpretação de vocábulo (verbi interpretatio). ${ }^{78}$ Porém, há o que Cícero chama de controvérsia em torno de antítese do escrito (disceptatio ex

\footnotetext{
${ }^{71}$ Part. XXVIII, $\$ 98^{\circ}$,

${ }^{72}$ Consideramos comparanda substantivado, como gerúndio.

73 Part. XXVIII, §99- $100^{\circ}$.

${ }^{74}$ Part. XXIX, $\S 101^{\circ}$.

${ }^{75}$ Part. XXIX, $\$ 102^{\circ}$, lin. 16-20.

${ }^{76}$ Part. XXIX, $\$ 102^{\circ}$. Segundo ERNESTI, as continentia correspondem a palavras que são reunidas por

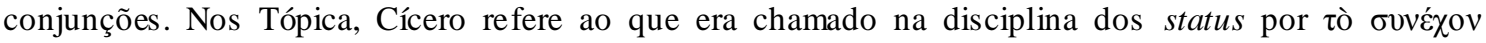
(parece-nos se tratar do particípio presente neutro de $\sigma v v \varepsilon ́ \chi \omega$, e corresponde ao continens latino), ou seja, que mantém reunido ou que junta, correspondendo às argumentações de defesa, sem as quais inexiste defesa, in: op. cit., p. 91. Para a tradução continentia por matéria, seguimos a versão de MENÉNDEZ PELA YO, op. cit., p. 263.

${ }^{77}$ Part. XXIX, $\$ 103^{\circ}$.

${ }^{78}$ Part. XXXI, $\$ 107^{\circ}$.
} 
scripti contentione), quando se controverte em ambigüidade de que propriamente significa; de escrito e intenção; qual dos dois deve o juiz seguir; sobre escritos contrários; qual dois deva ser aprovado. ${ }^{79}$

$\mathrm{Na}$ questão de conjetura, o acusador deverá considerar, sobretudo, a causa (causa) e o evento (eventus). Aquela significa a razão de provar (rationem efficiendi); esta, o que é provado (quod est effectum), ou seja, os sinais e vestígios passados, como se gravados. ${ }^{80}$

\section{CONCLUSÕES}

Do exposto, não obstante termos escolhido apenas alguns excertos do livro, podemos asseverar que Cícero tocou breve e completamente às divisões da arte a que se propôs. Isto com o propósito de ministrar lições ao seu filho. Podemos perceber que Cícero não fugiu às classificações tradicionais de sua época, provavelmente tendo em vista o motivo pedagógico da obra. Cícero teceu comentários sobre os gêneros de discurso deliberativo e judicial, ainda que não tenha sido nosso objeto de análise. Suas lições são muito claras, simples e, na maior parte das vezes, com exemplificações. Embora o propósito da obra seja o mais geral possível, dá-nos a impressão de que Cícero não a produziu tendo em mente outras referências senão a formação do advogado.

\section{REFERÊNCIAS BIBLIOGRÁFICAS}

ERNESTI, Johann Christian Gottlieb. Lexicon technologiae Latinorum rhetoricae: congressit et animad versionibus illvstravit Io. Christ. Theoph. Ernesti philos. Prof. Lips. Lipsiae: Svmtibus Caspari Fritsch, 1797.

GAINES, Robert N. Cicero's partitiones oratoriae and topica: rhetorical philosophy and philosophical rhetoric. In: Brill's Companion to Cicero: Oratory and Rhetoric. Edited by James M. May. Leiden: Brill, 2002.

GRANT, William Leonard. The Partitiones Oratoriae of Cicero: an introduction and commentary. A thesis presented in partial fulfillment of the requirements for the degree of doctor of philosophy in the department of classics at the University of Toronto, June,

\footnotetext{
${ }^{79}$ Part. XXXI, $\S 108^{\circ}$, lin. 26-30.

${ }^{80}$ Part. XXXII, $\S 110^{\circ}$, lin. 9-10.
} 
1943, p. 24-25. Texto disponível em:

<http://www.archive.org/details/partitionesorato00granuoft $>$. Acesso em 18.10.2009.

GRUBE, G. M. A. Educational, Rhetorical and Literary Theory in Cicero. Phoenix, 1962, XVI.

M. TVLLI CICERONIS. Rhetorica rec. brevq. adnot. crit. Instrvxit A. S. Wilkins, tomvs II, Oxonii e typographeo Clarendoniano, 1903.

OBRAS COMPLETAS DE MARCO TUlIO CICERÓN. Trad. D. Marcelino Menendez Pelayo.Tomo XIV (t. I da tradução). Madrid: Librería de los sucesores de Hernando, 1924. 